\title{
Edible Vaccine
}

The Future of Oral Vaccination

Department of Biotechnology, Veer Narmad South Gujarat University, Surat 395007, Gujarat, India.

Email: patelmahnoor786@gmail.com

\section{Abstract}

Edible vaccine is cost effective, easy in administration, easy in storage and safe vaccine delivery system. Edible vaccines are prepared by molecular pharming using the science of genetic engineering. Selected genes which are pathogenic can be isolated from the source and then introduced into the plants. That plant is now called transgenic plant and it is able to produce the encoded protein. That protein is pathogenic which is used to give the people as an edible vaccine. That protein is used for therapeutic purposes. It is less costly rather than another vaccine. Resistance to genetically modified food may affect the future of edible vaccine.

\section{Introduction}

Vaccines and antibodies play key role in healthcare. However, the cost of production is very high. Expression of an antigens as vaccine or antibodies against antigens of pathogens in transgenic plant is a convenient and inexpensive source for these immunotherapeutic molecules. These type of vaccines can be produced in edible plants, so that, plant can be eaten by the person to get immunized by that particular disease.

\section{Examples of Edible Vaccine}

1. Rabies vaccine produced in Tobacco.

2. Hepatitis B vaccine produced in Tobacco and Potato.

3. Gastroenteritis vaccine produced in Maize.

4. HIV vaccine produced in Tomato.

5. Cholera vaccine produced in Potato.

\section{Advantages}

1. Reduced need of the medical personnel and sterile injection condition.

2. Economical in mass production and transportation.

3. Therapeutic protein are free of other pathogens and toxins.

4. Storage near the site of use.

5. Edible, the way of administration.

6. Heat stable, eliminating the need of refrigeration.

7. Delivery of multiple antigens.

\section{Limitations}

1. Development of immune tolerance to vaccine peptide or protein.

2. Consistency of dosage from fruit to fruit, plant to plant and generation to generation is not similar.

3. Stability of vaccine in fruit is not known.

4. Evaluating dosage requirement is tedious.

5. Selection of best plant is difficult.

6. Certain foods like potato are not eaten raw, and cooking the food might weaken the medicine present in it.
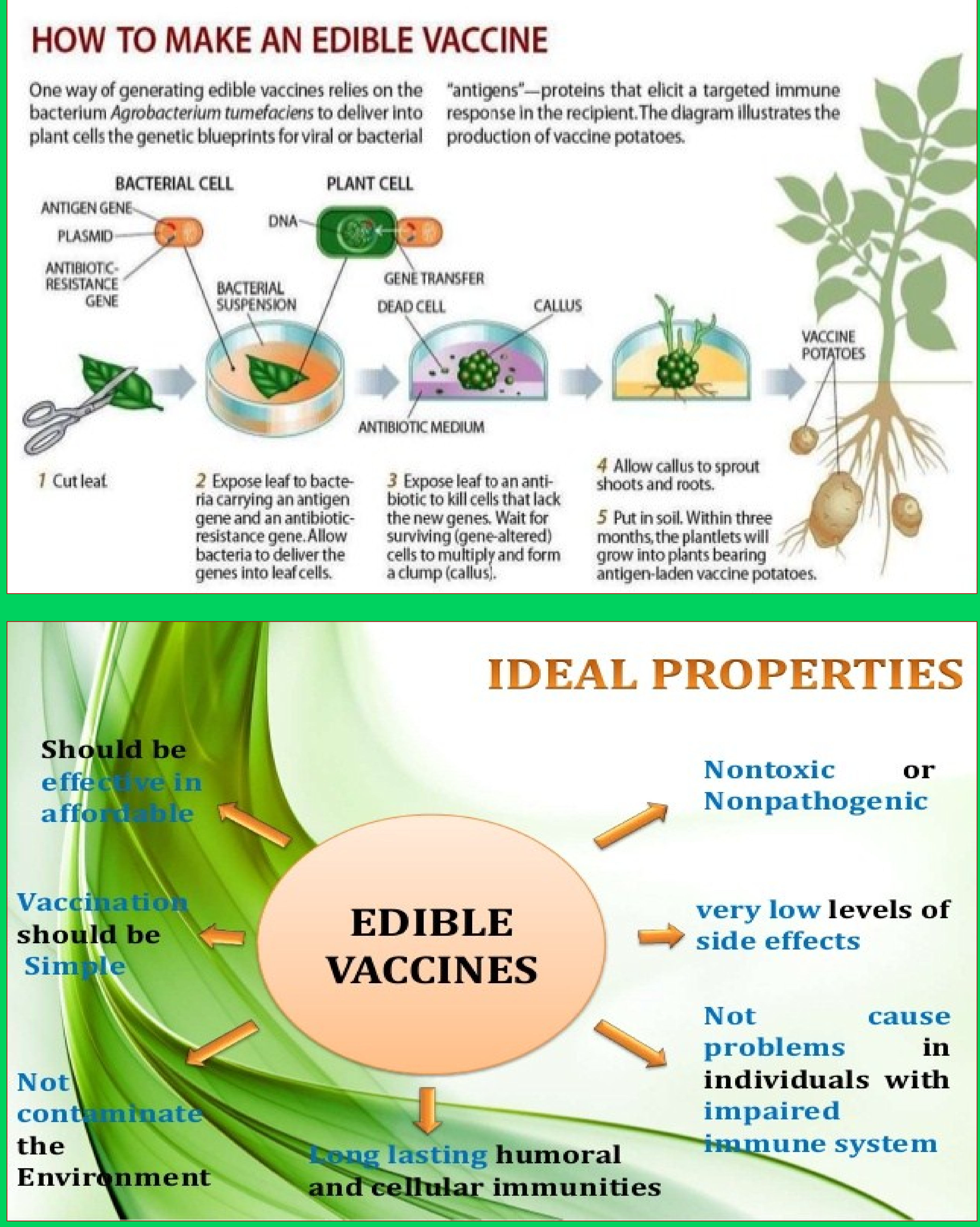

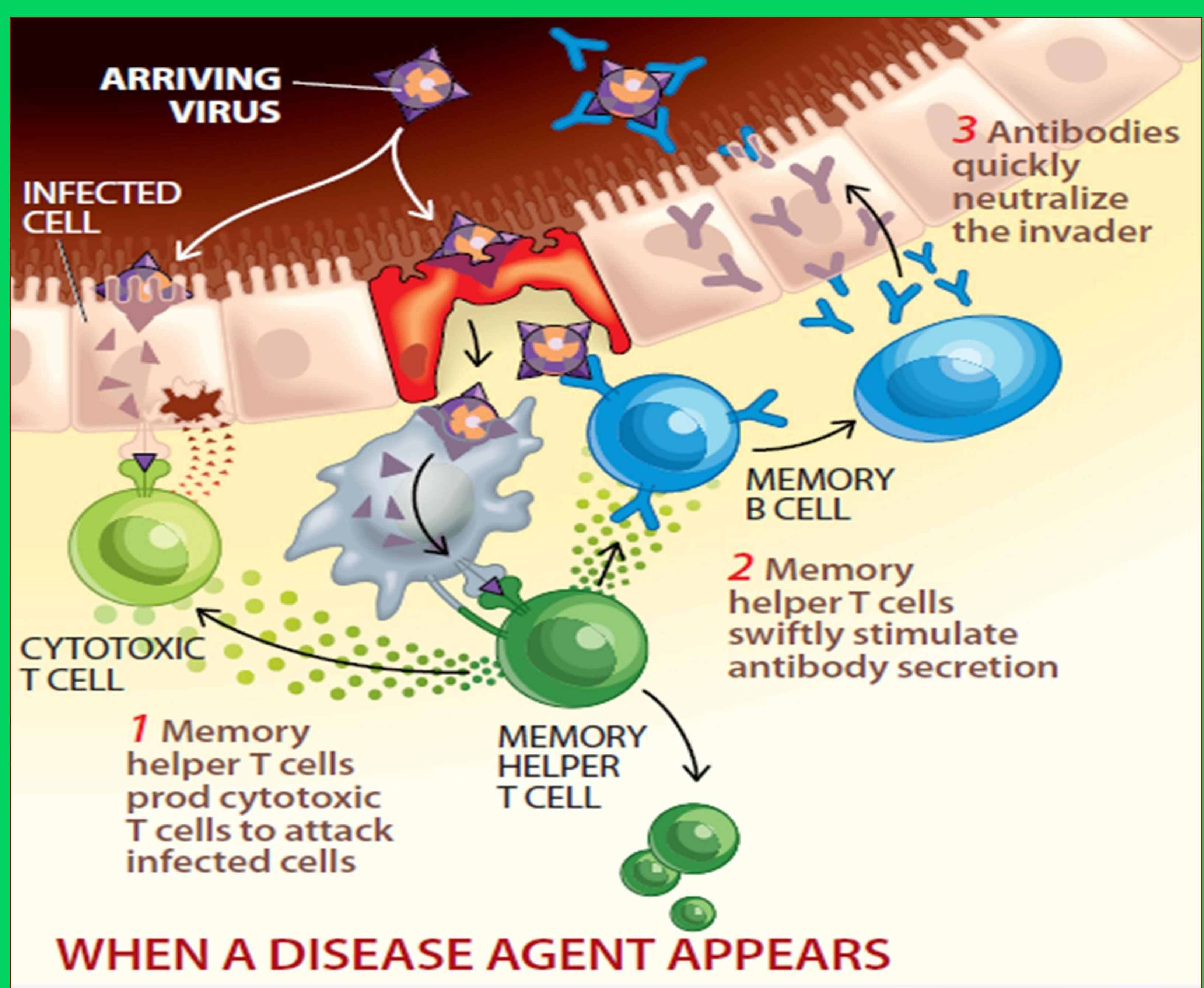

